\title{
Niemann-Pick Disease Presented with Cystic Lung Involvement
}

\section{Coşkun Doğan}

Clinic of Chest Diseases, Dr. Lütfi Kırdar Kartal Training and Research Hospital, İstanbul

\begin{abstract}
A 44-year-old female patient presented with the complaints of dyspnea on exertion, cough, and sputum. It was learned from her medical history that she had dyspnea for the last 1 year, and it increased with exertion; the complaints of cough and sputum began 1 month ago. Her physical examination revealed inspiratory rales in bilateral middle-lower regions, and posterio-anterior chest radiography showed reticular and reticulonodular infiltrates in bilateral middle-lower regions (Figure 1). Based on these findings, we planned to examine the patient for interstitial pulmonary disease (IPD). It was learned that she had a history of Niemann-Pick disease during childhood. Bilateral diffuse groundglass opacites, interlobular septal thickening in bilateral bases, and bilateral cystic lesions were observed in high-resolution thoracic tomography (Figure 2).
\end{abstract}

Respiratory function test and carbon monoxide diffusing capacity test findings of the patients were as follows: FEV /FVC: 88; FVC: 1.76 L, 64\%; FEV 1 : 1.54 L, 65\%; DLCO: 6.8 mL/mmHg/min, 30\%; and DLCO/NA: 2.87 $\mathrm{mL} / \mathrm{mmHg} / \mathrm{min}, 55 \%$. The patient had no risk factors that could lead to IPD such as occupational and environmental exposure, having a pet, history of drug use, and collagen tissue diseases. In the patient whose sputum ARB evaluation was negative, pulmonary involvement with Niemann-Pick disease was suspected. No endobronchial pathology was observed in the fiberoptic bronchoscopy, and her bronchoalveolar lavage was in cheilosis-lipidosis appearance (Figure 3). Bronchoalveolar lavage cytology was reported as "rare lymphocytes, which constitute approximately 5\%$6 \%$ of existent macrophages comprising giant histiocytes as well as sphingomyelin fiber-like structures and intracellular lipid vacuoles, consistent with clinical diagnosis, were observed in the ground of diffuse alveolar macrophages".

Pulmonary involvement with Niemann-Pick disease frequently presents with hepatosplenomegaly, hyperlipidemia, and macular degeneration, particularly in patients with type B form who survive up to adulthood (1). It results from lipid-loaded macrophages/his-

tiocytes invading the lung.

Corresponding Author

Coşkun Doğan

E-mail: coskund24@hotmail.com

- Available online at www.eurasianjpulmonol.com

The results of chest radiographies, high-resolution thoracic tomography, and respiratory function tests in these cases are similar to those in other IPDs.

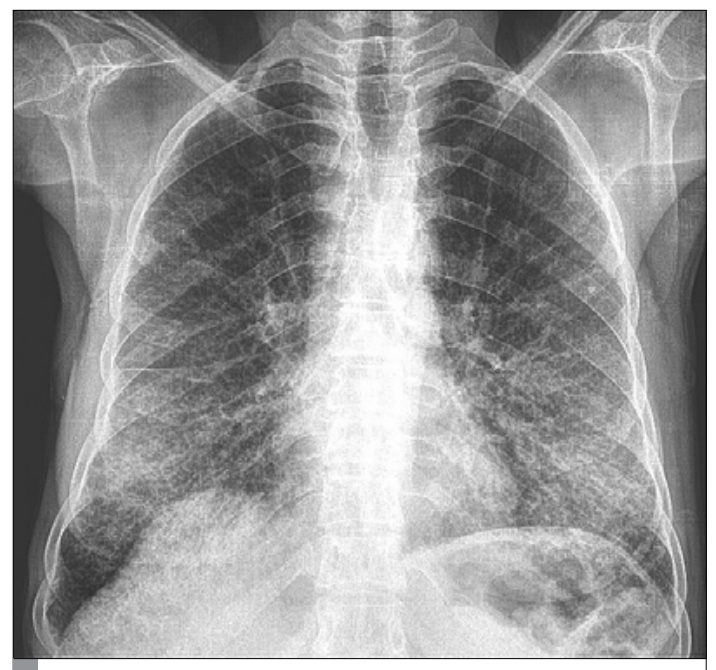

Figure 1. Reticular and reticulonodular infiltrates in bilateral middle-lower regions in posterior-anterior chest radiography 


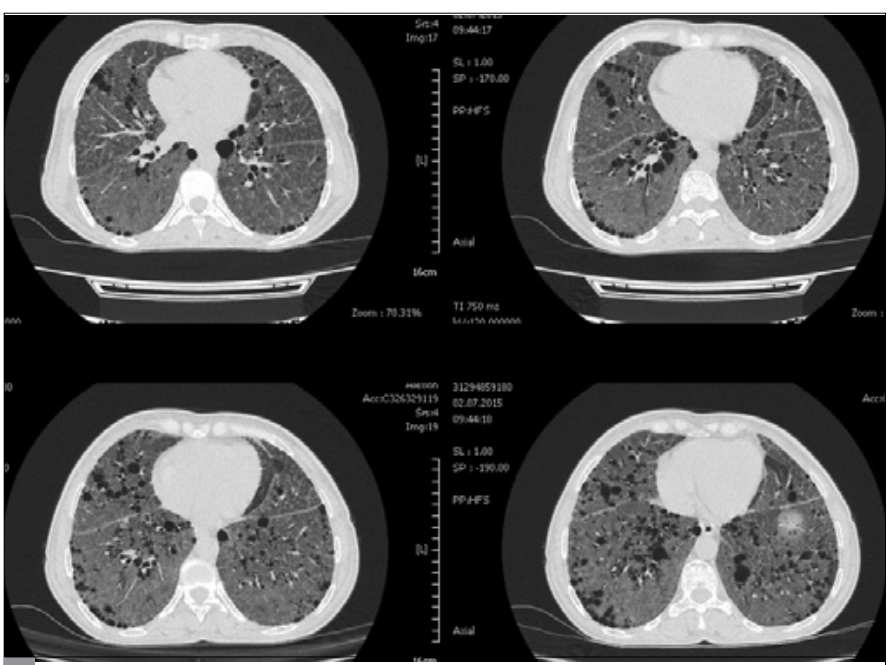

Figure 2. Bilateral diffuse ground-glass opacities interlobular septal thickening in bilateral bases, and bilateral cystic lesions observed in high-resolution thoracic tomography

The difference in our case from other cases reported in the literature and studies is that lung lesions displayed involvements as bilateral cystic lesions. Mendelson et al. (2) conducted a study on 52 cases including adults and children and examined the findings of thoracic tomographies taken for Niemann-Pick disease. In their study, no cystic involvement was reported in any case.

Peer-review: Externally peer-reviewed.

Conflict of Interest: No conflict of interest was declared by the authors.

Financial Disclosure: The authors declared that this study has received no financial support.

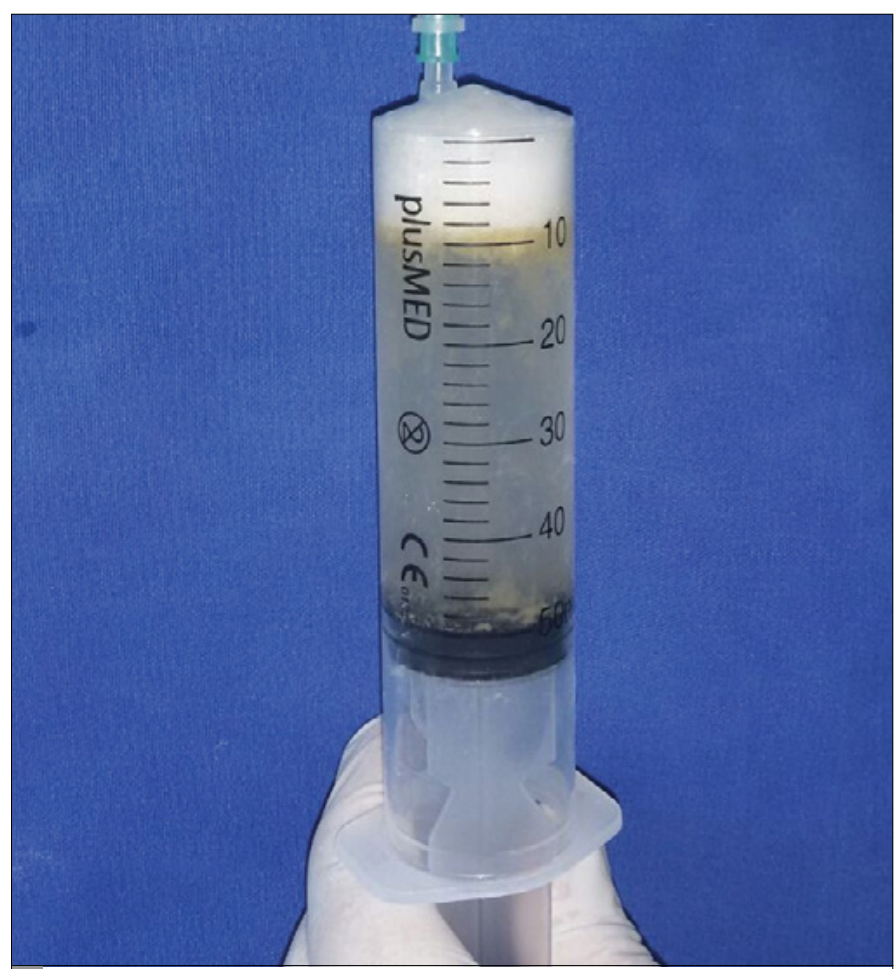

Figure 3. Bronchoalveolar lavage fluid in cheilosis-lipidosis appearance

\section{REFERENCES}

1. Zorlu P, Uçar Ş, Yaralı N, Demirçeken F. Nieman-Pick hastalığı tip A ve tip B: Iki olgu sunumu. Marmara Medical Journal 2014; 27: 54-7.

2. Mendelson DS, Wasserstein MP, Desnick RJ, Glass R, Simpson W, Skloot G, et al. Type B Niemann-Pick disease: findings at chest radiography, thin-section, and pulmonary function testing. Radiology 2006; 238: 339-45. [CrossRef] 